needed to safeguard the health of Syrian refugee child workers.

\section{P-93 HOW CAN WE GET COMPARABLE EXPOSURE DATA ACROSS COUNTRIES? A WORKERS' SURVEY ON EXPOSURE TO CANCER RISK FACTORS IN EUROPE - AN INNOVATIVE APPROACH}

${ }^{1}$ Nadia Vilahur, Marine Cavet. 'EU-OSHA, Spain

\subsection{6/OEM-2021-EPI.196}

Introduction With cancer accounting for an estimated 53\% of all work-related deaths in the European Union, data on exposure to known cancer risk factors at work are essential to improve the safety and health of workers, support the evaluation of existing policies and foster a productive and sustainable economy.

Objective Recognising the lack of harmonised figures at European level, and having carried out a feasibility study, the European Agency for Safety and Health at Work (EU-OSHA) has started a workers' survey on exposure to cancer risk factors following the Australian Workplace Exposure Studies (AWES) model. The objective of this initiative, which plans to publish first findings in 2023, is to identify the most prevalent cancer risk factors across occupations and sectors in Europe.

Methods EU-OSHA will initially carry out the survey in six European countries, interviewing a representative sample of workers about their current job. Based on the respondent information on specific tasks performed at work, exposure data to one or more cancer risk factors will be derived for each worker, using the occupational exposure assessment tool for epidemiological studies (OccIDEAS), an algorithm using epidemiological data, workplace measurements and expert assessment, which EU-OSHA is adapting to the European context.

Results The survey looks into the number and characteristics of the workers exposed to a range of cancer risk factors, including asbestos, benzene, chromium, diesel exhaust, nickel, silica dust, UV radiation, wood dust, among others. Information on workers' multiple exposures and the use of control and protective measures at work will be available. Results can be analysed by activity sector, occupation, country, gender, etc. Conclusion To provide an overview of the methodology and adaptations of the Australian model to Europe, and to discuss the limitations of the survey and the challenges in adapting it to national contexts.

\section{P-98 RELATIONSHIP BETWEEN PRESENTEEISM AND QUALITY OF LIFE: THE ROLE OF SOCIAL SUPPORT}

${ }^{1}$ Sónia Isabel Costa Magalhães, Joselina Maria Pinto Barbosa, Elisabete Maria Neves Borges. 'ICBAS, Portugal

\subsection{6/OEM-2021-EPI.197}

Presenteeism is defined as the practice of being present at work, but unable to fully perform tasks due to physical and/ or mental health problems. Research on presenteeism highlights its consequences for people's health and quality of life, as well as the loss of productivity of organizations. Social support at work by supervisors and colleagues, can contribute to the minimisation of the wear and health risks of these professionals.

Thus, the purpose of this research is to i) explore the prevalence of presenteeism in higher education professionals, ii) identify the main health problems behind it, and iii) identify personal, professional and social support factors associated with the phenomenon. Additionally, it is intended to evaluate the role of social support at work in relation to presenteeism and quality of life.

The target population will be made up of higher education technicians and it will be developed at the University of Porto, a Portuguese public university located in Porto. The study will be conducted in the form of a survey, with data being gathered via email. We will apply the validated versions for the Portuguese population, the Presenteeism Scale (SPS-6), the subscales, 'social support from supervisors' and 'social support from colleagues' of the Copenhagen Psychosocial Questionnaire, COPSOQ (to measure social support at work) and the Quality of Life Index (EUROSHIS-QOL-8). A sociodemographic questionnaire (with personal and work-related variables) will also be collected.

We expect with this study to contribute to the identification of reduced activity professional patterns associated with presenteeism and that affect professionals quality of life, as well as alerting institutions to the relevance of promoting social support at work.

\section{\begin{tabular}{|l|l}
\hline P-99 & RESPIRATORY, AUDITORY AND VISUAL IMPAIRMENT
\end{tabular} AMONG SPONGE IRON PLANT WORKERS IN GOA, INDIA: A COMPARISON STUDY}

${ }^{1}$ Vishwaraj Mhalshekar, Jagdish Cacodcar, Annet Oliveira, Sweta Mhalshekar. ${ }^{1}$ Goa Shipyard Limited, India

\subsection{6/OEM-2021-EPI.198}

Sponge iron plant workers are exposed to excessive dust at raw material handling section, fumes emitted during the burning process, and to the noise generated throughout till the formation of final product poured in moulds to form sponge iron.

Objective The study was done to compare the respiratory, auditory and visual impairment among the workers exposed to the dust, fumes and noise with those less likely to be exposed to these hazards in the same work place.

Methods The present study was carried out among all the 578 workers in a sponge iron plant in Goa. The spirometry, audiometry and the near and far vision findings were obtained from the routine annual medical examination records for the year 2019. Data was analyzed to compare the morbidity among the exposed group $(n=359)$ i.e., the workers directly exposed to dust, fumes and noise with those less likely to be exposed $(n=219)$ i.e., the executives and the office staff working in closed air-conditioned offices segregated from the site of hazards.

Results Respiratory impairment among those exposed to dust and fumes was 1.6 times higher than the unexposed. The hearing impairment among those exposed to noise was 1.8 times higher than the unexposed. The impairment in near vision in the exposed was 1.3 times higher than the nonexposed whereas the impairment in far vision was 1.3 times higher among the non-exposed as compared to the exposed. 